\title{
Experience with on-line computing in clinical chemistry
}

\author{
L. G. WHITBY AND D. SIMPSON \\ From the Department of Clinical Chemistry, The Royal Infirmary, Edinburgh
}

The scientific practice of medicine is making increasing demands upon clinical chemistry departments and it is the experience of these laboratories, both in teaching and non-teaching hospitals, that their work loads double every four to five years (Lathe and Mitchell, 1966). The use of AutoAnalyzers ${ }^{1}$ has markedly increased the capacity of these laboratories for carrying out repetitive types of analytical work (Table I), and at the same time introduced a degree of much needed uniformity into the methods of performing analyses. Developments in automatic chemical equipment may further increase the work capacity of these departments, but already a different set of problems has emerged. These can be summarized under several interrelated headings: (1) specimen collection and unequivocal identification of samples with the correct patient throughout the subsequent procedures; (2) accession procedures in the laboratory; (3) maintenance of reliable standards of analytical performance in large-scale operations; (4) processing of instrumental readings; (5) report preparation and presentation; (6) uses made of laboratory data $(a)$ by the clinicians and $(b)$ by the laboratory; (7) records storage and arrangements for their retrieval for various purposes.

This paper will concentrate particularly on experience gained so far with computer-dependent systems designed to help with problems 2 to 5 .

Blaivas and Mencz $(1967,1968)$, reporting upon an extension of their earlier system (Blaivas, 1966), described how an IBM 1710 computer had been routinely used for process control, linked on line to as many as $\mathbf{3 0}$ AutoAnalyzers performing up to 20 different analyses. The reasons for wishing to develop an alternative to the system in use at King's County Research Laboratories included the substantial cost (capital or hire) of the IBM system, and the desire to incorporate additional features such as records storage and cumulative reporting of laboratory results using the computer. The system recently installed in this laboratory is intended ultimately to help with problem 7 also, by storing records of laboratory work in a way that will allow the issue of

${ }^{1}$ Technicon Instruments Co., Chertsey, Surrey.
TABLE I

THE PRODUCTIVITY OF A CLINICAL CHEMISTRY LABORATORY ${ }^{1}$

\begin{tabular}{ccccc} 
Year & $\begin{array}{l}\text { Work Load } \\
\text { (Determinations) }\end{array}$ & Technicians & $\begin{array}{l}\text { AutoAnalyzers } \\
\text { (Number of } \\
\text { Channels) }\end{array}$ & \\
\hline 1955 & 57,000 & 14 & - & 4,000 \\
1960 & 106,000 & 18 & 1 & 6,000 \\
1963 & 195,000 & 23 & 3 & 8,500 \\
1966 & 407,000 & 30 & 12 & 13,500 \\
1968 & 506,000 & 33 & 15 & 15,300
\end{tabular}

${ }^{1}$ Data from the Department of Clinical Chemistry, Royal Infirmary, Edinburgh.

${ }^{2}$ Productivity is expressed as the average number of determinations performed annually by each member of the technical staff.

cumulative reports similar to those previously prepared manually (Whitby and Owen, 1965).

With AutoAnalyzers other than the SMA-12 series, an important data-acquisition and calculation problem exists in the need to convert raw analytical data, as represented by long series of peaks on chart records, into numerical results for entry on reports. This demands the examination of each peak, since variations in shape may indicate instrumental malfunction or faulty chemical analysis, the reading and checking of peak heights, the application of corrections for instrumental drift, the interpolation of corrected readings in relation to the appropriate pairs of standards, calculation of concentrations, and entry of calculated results into the laboratory's records and on to report forms. With several AutoAnalyzer channels operating at 40 or 60 samples/hour, the number of repetitive processes involving checking and calculation to be performed daily in a busy laboratory is formidable.

To help with these computations, in 1966 this department installed an Elliott Automatic Laboratory Analysis ${ }^{2}$ (ALA) system for data acquisition from five channels of AutoAnalyzer equipment and processing by an Elliott 803 computer. The features of the ALA system have been fully described (Flynn, 1965, 1966; Flynn, Piper, and Roberts, 1966), and this laboratory's experience with the equipment has been reported (Whitby, Proffitt, and McMaster,

${ }^{2}$ Elliott Automation Ltd, Borehamwood, Herts. 


\section{TABLE II}

SHORTCOMINGS OF THE ELLIOTT ALA SYSTEM OF DATA ACQUISITION FROM AUTOANALYZERS FOR PROCESSING BY A COMPUTER OFF-LINE ${ }^{1}$

A Long chain of components involved, each liable to failure

(1) Mechanical peak (or trough) recognition system-shaft encoders

(2) Translator timers and programmer unit for processing signals from shaft encoders

(3) Paper-tape punch for collecting analytical data on punched tape

(4) Teletype unit in laboratory, used for

(a) preparing patient identification data on a second tape

(b) preparing a third tape detailing positions of standards and identification of errors

(c) transmitting these three tapes to another Teletype unit in the computer centre

(5) Elliott 803 computer with output of results on paper tape

(6) Transmission of results tape back to laboratory for printout

B Consequences of large work load and resulting arrival of computed data near the end of the working day

(1) Disruptive effects of minor hold ups in sequence of data-transmission and data-processing operations

(2) Failure sometimes to detect faults in analytical operation until printout able to be examined

(3) Results required urgently have to be calculated by laboratory staff and issued as preliminary reports.

C Other shortcomings

(1) Inability to handle the full load of plasma urea and electrolyte analyses because data acquisition from AutoAnalyzers has to stop about $3 \mathrm{pm}$

(2) Capital cost of about $£ 1,500$ per channel for ALA equipment, ie, apart from cost of the AutoAnalyzers themselves

(3) Shaft-encoder too bulky to be fitted into a twin-channel recorder

${ }^{1}$ From Whitby et al (1968).

1968); the advantages described by Flynn and his colleagues were confirmed, but these had to be offset against the disadvantages inherent in the acquisition of data from AutoAnalyzers for batch processing at the end of an analytical run by a remote computer off-line (Table II). Experience gained with the off-line ALA system was, however, valuable in helping to define features that should be incorporated into the Elliott Automatic Biochemical Laboratory (ABL) system. The ABL system was delivered in May 1968, and installation and manufacturers' standard acceptance tests were completed in July 1968. Since then investigations have been in progress to evaluate, step by step, the programs which had been written on the basis of detailed systems analysis and specifications carried out jointly by the staff of Elliott Automation Systems Ltd and the staff of this laboratory in the previous 18 months.

The components of hardware installed in the laboratory are detailed in Table III. One room, area $200 \mathrm{sq} \mathrm{ft}$ and centrally placed, required minor modification with provision of an intake of filtered air; it accommodates these various items,

\section{TABLE III}

\section{HARDWARE CONFIGURATION}

Central processor Elliott 903 computer; 8k core store (18-bit word) Backing store Magnetic tape controller and three handlers (Ampex TM7; $9 \mathrm{kch} / \mathrm{sec}$ ).

Input devices

On-line Teletype (model 33)

Paper tape reader $(250 \mathrm{ch} / \mathrm{sec})$

Data-acquisition unit, receiving signals on-line from AutoAnalyzers via (up to four) analyser consoles

Output devices On-line Teletype (same unit as input Teletype; $10 \mathrm{ch} / \mathrm{sec}$ )

On-line IBM output writer $(15 \mathrm{ch} / \mathrm{sec})$

Paper tape punch $(100 \mathrm{ch} / \mathrm{sec})$

Off-line Teletype (model 33; $10 \mathrm{ch} / \mathrm{sec}$ )

Spare units Paper tape reader and punch

Off-line Teletype can serve as spare for on-line unit. with the exception of the analyser consoles which are placed on the laboratory benches. The individual components were all standard products apart from the data-acquisition unit and the analyser consoles; these had to be developed as well as the systems programming, the development being carried out with the support of the National Research Development Corporation.

\section{MONITORING AUTOANALYZERS ON-LINE TO THE COMPUTER}

MONITORING OF EQUIPMENT Previously described methods of data acquisition on-line from AutoAnalyzers (Blaivas, 1966; Blaivas and Mencz, 1967, 1968; Gould, 1968; Gray and Owen, 1968) have all taken their signals from the chart recorder, but the ABL system takes its signals from the standard AutoAnalyzer colorimeter or flame photometer: so far, other detector units, such as the multichannel colorimeter used in the SMA-12 system or the fluorimeter unit, have not been linked to the Elliott data-acquisition unit. Instead of the signal from the colorimeter being transmitted direct to the recorder, as in the standard method of operating AutoAnalyzers, the separate signals from the reference and measuring photocells in the colorimeter are led to an analyser console, developed by Elliott Automation; here they are each amplified for transmission to the data-acquisition unit (the length of linking cable is about 60 feet). The analyser console also attenuates part of the amplified signals for separate transmission to the AutoAnalyzer recorderamplifier unit; a visible record of each channel's operation is thereby retained. (The importance of retaining these chart records will be discussed later.)

The optimum settings of the colorimeter controls 


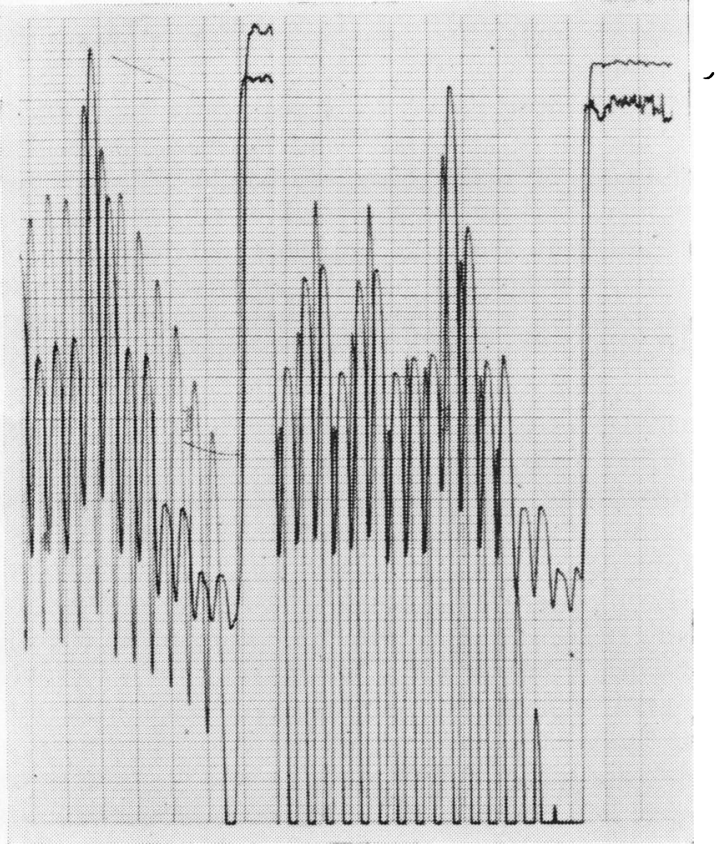

FIG. 1.

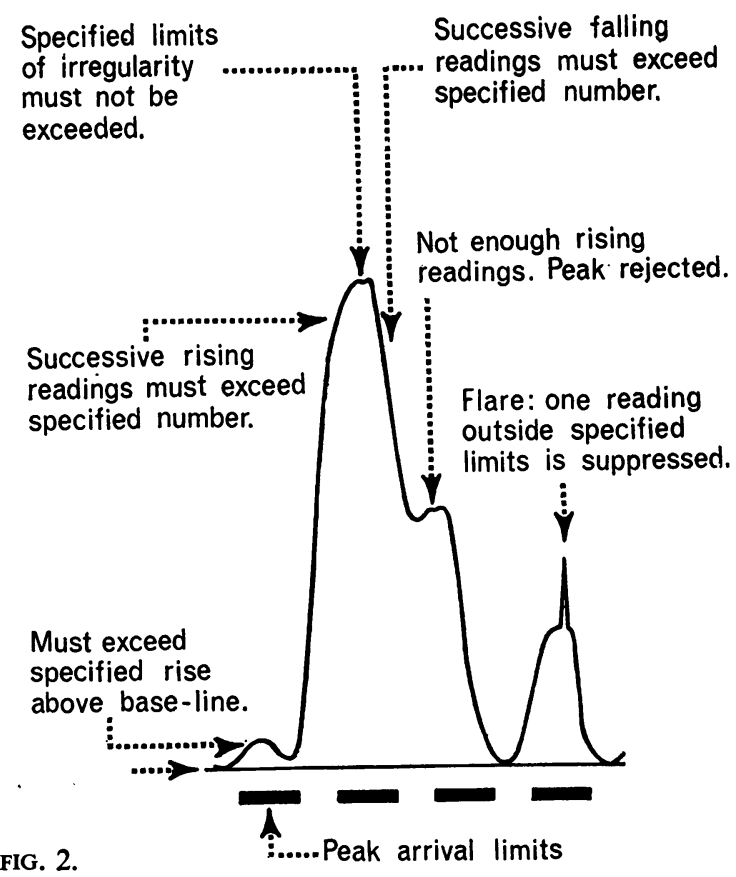

FIG. 1. AutoAnalyzer chart records of calibration curves for sodium and potassium determinations (a) with the usual backing off on the sodium channel (lowest standard on scale 100 m-equiv/l) and (b) without backing off when the signals reached the recorder via the Elliott analyzer console.

FIG. 2. Elements of the peak recognition program. Signals from the reference and measuring photocells are read and digitized every two seconds (for details, see text and Table V).

when signals are to be transmitted to the computer differ in some instances from those selected for the usual operation of AutoAnalyzers. Details of the analytical methods are included in Table VIII; all the methods, except sodium and potassium determinations, employed tubular flow cells, and examples of the extent of changes required in control settings on the colorimeters are summarized in Table IV. The only channel in which the introduction of online monitoring has led to a significant modification in the appearance of the final chart record has been the sodium channel. With these analyses, when the Elliott analyser console is in use, the display on the
AutoAnalyzer recorder is no longer backed off with the result that the chart width for sodium, instead of covering the range from approximately 90 to 170 m-equiv/l, runs from 0 to about $180 \mathrm{~m}$-equiv/l (Fig. 1); this gives rise to some loss of precision if the operator has to read these charts and calculate results from the chart records from a run in which the computer has been set to monitor the sodium channel's performance.

PEAK RECOGNITION BY COMPUTER Several of the features of the peak recognition programs are similar to those previously described (Blaivas, 1966;

TABLE IV

EXAMPLES OF COLORIMETER SETTINGS

\begin{tabular}{|c|c|c|c|c|c|c|}
\hline \multirow[b]{2}{*}{ Method } & \multicolumn{2}{|c|}{ Standard AutoAnalyzer Operation } & \multirow[b]{2}{*}{$\begin{array}{l}100 \% T \text { Control } \\
\text { Setting }\end{array}$} & \multicolumn{2}{|c|}{ Elliott Analyser Console Inserted } & \multirow[b]{2}{*}{$\begin{array}{l}100 \% \mathrm{~T} \text { Control } \\
\text { Setting }\end{array}$} \\
\hline & $\begin{array}{l}\text { Nominal } \\
\text { Aperture }\end{array}$ & $\begin{array}{l}\text { Area of } \\
\text { Aperture }(\mathrm{sq} \mathrm{cm})\end{array}$ & & $\begin{array}{l}\text { Nominal } \\
\text { Aperture }\end{array}$ & $\begin{array}{l}\text { Area of } \\
\text { Aperture }(\mathrm{sq} \mathrm{cm})\end{array}$ & \\
\hline $\begin{array}{l}\text { Urea } \\
\text { Cholesterol } \\
\text { Uric acid } \\
\text { Phosphate } \\
\text { Bicarbonate }\end{array}$ & $\begin{array}{l}9 \\
8 \\
8 \\
6 \\
6\end{array}$ & $\begin{array}{l}1 \cdot 61 \\
1 \cdot 27 \\
1 \cdot 27 \\
0 \cdot 86 \\
0 \cdot 86\end{array}$ & $\begin{array}{l}644 \\
765 \\
606 \\
861 \\
957\end{array}$ & $\begin{array}{l}3 \\
2 \\
2 \\
2 \\
1\end{array}$ & $\begin{array}{l}0.50 \\
0.42 \\
0.42 \\
0.42 \\
0.33\end{array}$ & $\begin{array}{l}220 \\
754 \\
210 \\
916 \\
367\end{array}$ \\
\hline
\end{tabular}

Settings unchanged: Chloride, alkaline phosphatase, calcium, creatinine (also unchanged on sodium, potassium; flame photometer). 

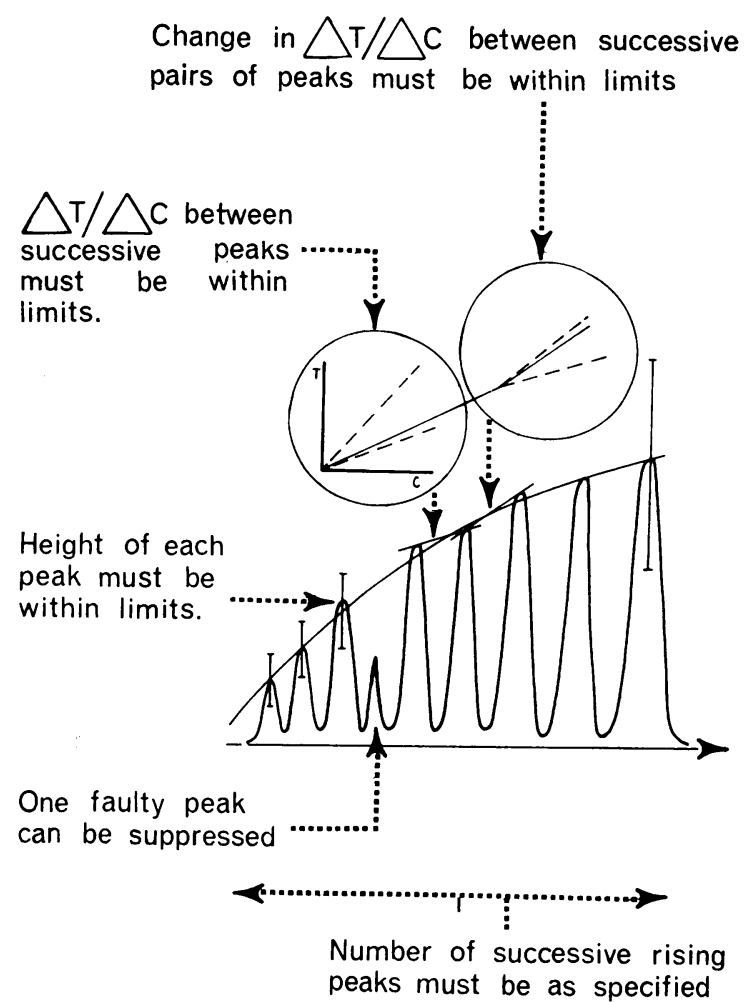

FIG. 3. Elements of the calibration curve validation program. Each peak is examined by the peak recognition program. The change in peak height between successive peaks is expressed as the difference in percentage transmission for the stated increment of concentration, and thus represents the gradient $\Delta T / \Delta C$ of a straight line.

Blaivas and Mencz, 1967, 1968; Gould, 1968), and are summarized in Figure 2 . The continuously varying electrical voltages from the measuring and the reference photocells corresponding to each analytical channel are amplified in the analyser consoles for transmission to the computer, and the data-acquisition unit receives these two signals from each channel regularly every two seconds. The analogue signals are then digitized for input into the computer.

As shown in Fig. 2, for a peak to be recognized, the height of the peak must exceed a specified minimum distance above the baseline. Except for a few analyses, eg, protein blank, this minimum rise is derived from the usual analytical behaviour of the lowest standard on the calibration curve, and the specification of a minimum rise means that peaks with heights lower than the first standard are rejected for calculation purposes. With protein blanks, readings for calculations are taken on a timed basis, starting from a first peak of easily recognized proportions, and linear extrapolation between the baseline and the lowest standard is permitted, ie, no minimum rise is stipulated for protein blanks.

Each peak, to be accepted, must have a number of $\overrightarrow{0}$ rising readings and a number of falling readings each $ᄋ$ of which exceed a specified number, and acceptable limits of irregularity on the ascending and descend- $c$ ing limbs of a peak as well as across the top of a peak are specified. Collectively these limits serve to detect and reject peaks swamped by carryover from the preceding analysis and double peaks. The program allows for the acceptance of a peak that is deformed on the chart record by the appearance of a flare (usually due to an air bubble passing through the colorimeter), as long as there is only one irregular signal generated by this disturbance. One further criterion laid down is the time limit within which peaks can arrive at the colorimeter for them both to be recognized and accepted. Examples of the data required in specifying the peak recognition program for each channel are shown in Table V.

CALIBRATION CURVE VALIDATION Each run of analyses begins with a set of calibrating standards, and the computer program searches for and attempts to validate the calibration curves, basing this validation on several criteria (Fig. 3). The individual criteria have been given wide limits, but collectively 9 they make up a demanding set of requirements, $D$ summarized as follows: (1) Each peak is examined for acceptability by the peak recognition program.

TABLE V

EXAMPLES OF PEAK RECOGNITION PARAMETERS

Calcium Cholesterol

Uric
Acid

50

A Rate of analysis (samples/hour)

B Expected number of readings between peaks

C Width of window (seconds)

D Minimum number of rising readings

E Minimum number of falling readings

F Maximum irregularity in rise or fall ${ }^{1}$

G Maximum difference between successive readings

H Minimum rise required

1The units for columns $F$ to $H$ are the number of transmission lines on the chart record. 


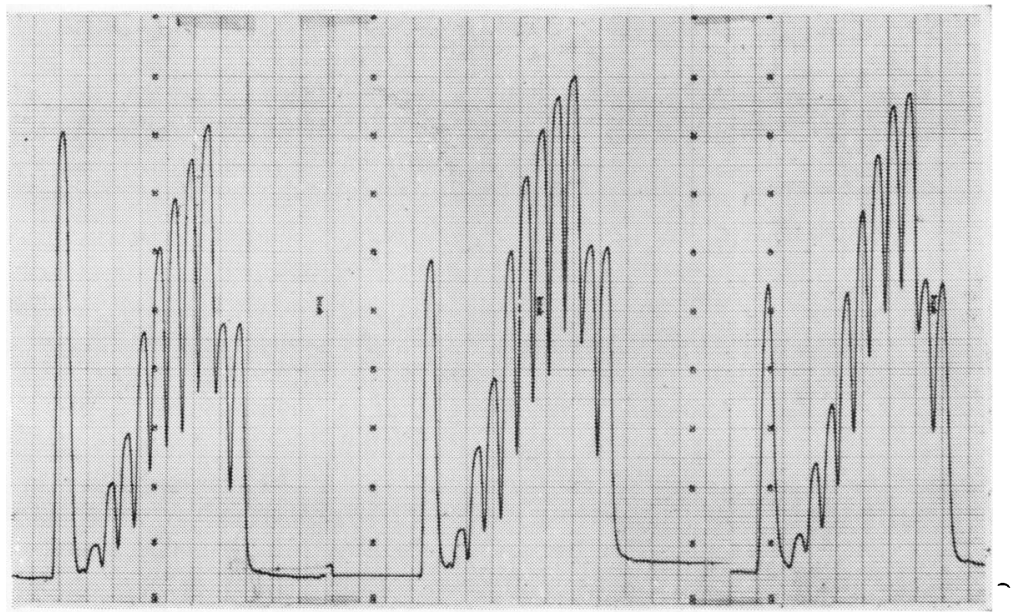

FIG. 4. Examples of calibration curves for urea analyses. Left: curve close to lower limit of acceptable height. Middle: high curve accepted after operator's instruction. Right: curve with one faulty standard accepted after operator's instruction.
(2) The heights of individual calibration standards must fall within specified limits. (3) Gradients between adjacent pairs of standards forming part of the overall curve must fall within specified limits; these gradients express the relationship between change in signal generated as a result of analysing pairs of standards and the difference in concentration between the corresponding pairs of standards (shown in the left-hand inset to Fig. 3 as $\Delta \mathrm{T} / \Delta \mathrm{C}$ ). (4) Changes in gradients between successive segments of the calibration curve must not exceed specified limits (shown in the right-hand inset to Fig. 3). (5) Overall recognition of the appropriate number of peaks, occurring in the prescribed sequence. (With multichannel analyses, calibrating standards for each analysis cannot always be analysed in progressively rising order of concentration.)

Data describing the characteristics of each calibration curve were defined initially from study of at least 20 curves for each channel, obtained with standard AutoAnalyzers during analytical runs on different days; some of these data were modified on the basis of experience gained later during on-line monitoring of the AutoAnalyzers with the Elliott 903 computer.

As Fig. 3 indicates, the individual calibrating standards can be accepted within wide limits as long as they satisfy the peak recognition program, but the gradient between successive pairs of peaks must fall within defined limits, and flat calibration curves have been rejected because these minimum differences between standards have not been exceeded; similarly, excessively steep calibration curves have been rejected by this criterion. If the gradient observed between one pair of peaks differs from the mean of the stipulated values, the extent to which the gradient on the succeeding segment of the calibration curve can be accepted is narrowed, a set of criteria for acceptable changes in gradients between adjacent segments having also been defined. These points about gradients are shown diagrammatically in Fig. 3, and a selection of calibrating curves illustrating some of these points is shown in Figure 4.

The program allows for the use of a faulty calibration curve in which either the top or the bottom standard is rejected, or else one of the intermediate standards is faulty (Fig. 4). However, before the curve can be used for calculation purposes, an error message appears on the on-line Teletype; after inspection of the recorder trace, the computer can be instructed to use the imperfect calibration curve, but this decision may carry disadvantages. If an end standard has been lost and the computer is instructed to use the curve, it thereafter calculates on the basis of a reduced set of standards; this will have the effect that more results for specimens are unable to be calculated if their concentrations fall outside the shortened calibrating curve. With loss of an intermediate standard (Fig. 4), the computer applies linear interpolation over a wider interval, with possible loss of accuracy over the affected part of the curve.

Immediately following acceptance of a calibration curve, a message to this effect appears on the on-line Teletype. If the computer fails to find the calibration curve by the expected time, however, it continues to search for the pattern of standards that together make up the calibration curve, and it cannot be used to monitor the analysis of samples from patients until the curve has been found. Since the operator is informed immediately the calibration curve has 


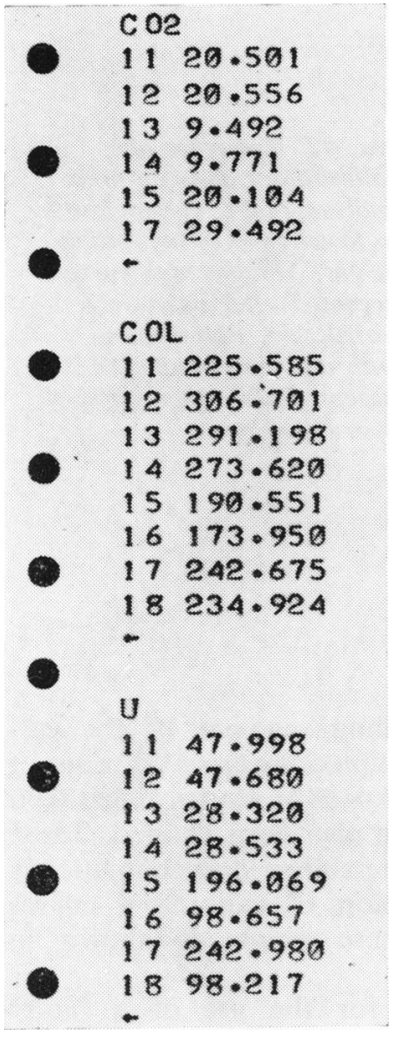

FIG. 5. Results for batches of bicarbonate, cholesterol and urea results printed up off line by Teletype. Computed results processed in batches of 10 , with results only printed out for the first eight positions, ie, those allocated to patients' specimens or control samples (specimens 16 and 18 on bicarbonate channel had been rejected).

been accepted, there is normally no delay at this stage in starting the analysis of patients' specimens, assuming the curve was satisfactory.

CORRECTION FOR DRIFT AND CALCULATION OF CONCENTRATIONS Following acceptance of a calibration curve, the computer continues to search for and validate peaks and the analysis of samples from patients proceeds, except that positions 10 and 20 , and every 10th position thereafter, contain a drift correction standard. At the completion of each batch of 10 analyses, assuming that the drift standard was satisfactory, the computer program applies a linear correction for any drift that has occurred to each acceptable intervening peak. This correction is applied to the highest single reading (excluding flairs) observed on each peak, and the program thereafter uses the corrected values for calculation purposes, interpolating these in relation to the appropriate pairs of standards on the calibration curve.

In due course, calculated concentrations are to be held on the magnetic tape backing store but, at the present stage of assessment, results are punched out

in batches by the paper-tape punch and printed up off line on the Teletype (Fig. 5). The acceptability of the drift standard in each 10th position is assessed against the peak height of the corresponding standard in the calibration curve, and error messages are printed out if drift has exceeded specified limits either upwards or downwards. Under these circumstances, a decision has to be taken by the operator whether to continue analyses on that channel; while awaiting the instruction, the computer continues to search for the peaks that follow the faulty drift standard. Assuming that a decision to continue analyses is taken, the reading for the faulty drift is cancelled and concentrations are then calculated over a double interval, with application of a linear correction for drift to the previous 20 peaks after the peak corresponding to the succeeding drift standard has been recognized and accepted. It is possible to continue monitoring peaks after failing to detect two successive drift standards by typing in the appropriate instruction, but this is regarded as an unlikely requirement, quite apart from the doubtful validity of such an instruction on analytical grounds.

Immediately preceding the drift standards (in cup positions $19,29,39$, etc), samples from a pool of quality control serum can now be placed. The program does not provide for the concentrations observed with this pool to be printed out unless a value is observed which differs by more than a specified amount from the figures stored in the computer. When the acceptable limits are exceeded, the latest set of observations together with the two preceding sets of values are to be printed out on the on-line Teletype. This feature of the program has not yet been fully tested, and the printout (Fig. 5) corresponds to an analytical run in which positions 19, 29, etc, were occupied by drift correction standards identical in composition with those occupying positions 20,30 , etc. It is important to standardize the conditions under which the drift correction standards in positions 20,30 , etc, are analysed, and this can either be achieved by placing another identical sample in the preceding cups, as was the practice adopted with the ALA system (Flynn, 1965), or by standardizing for a run the composition of the samples in positions 19,29 , etc, for instance by using a quality control pool of specified composition, and of composition sufficiently close to the drift correction standard for the latter not to be affected adversely by carryover.

ANALYSIS OF SPECIMENS: SUMMARY OF PROGRESS Peak recognition, calibration curve validation, and drift correction programs have been assessed for 20 analytical channels (listed in Table VII); these features have all been satisfactorily validated except 


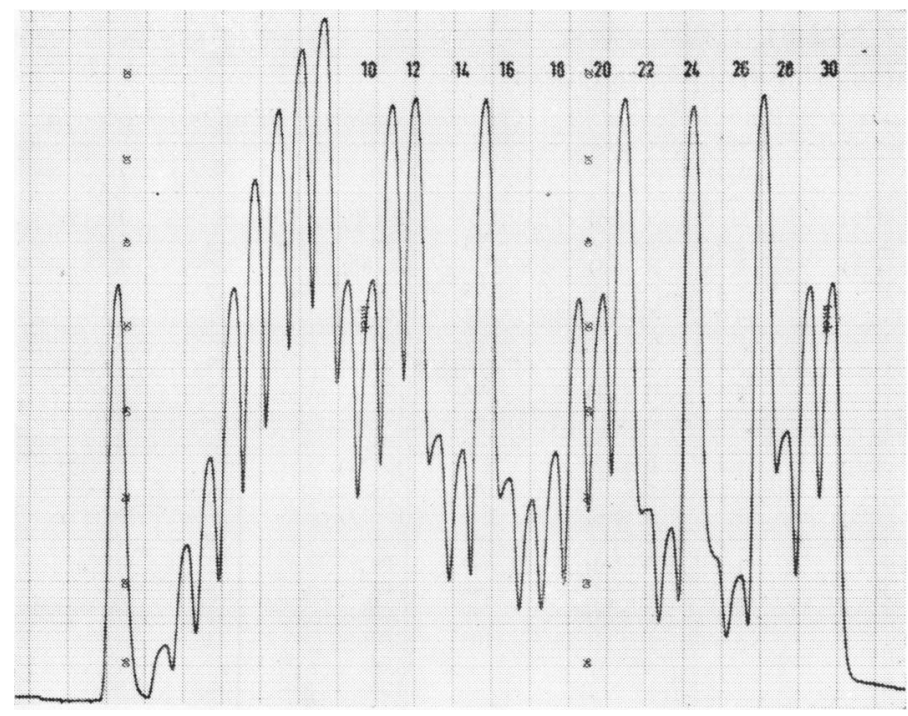

FIG. 6. Recognition of interaction between specimens by the computer (urea analyses, 60/h; sample: wash ratio, 2:1). Positions $11,12,15,21,24$, and 27 occupied by a pool of plasma having a high concentration of urea. Positions 13 and 14, 16 and 17, 22 and 23, 25 and 26 occupied by pairs of plasma samples having progressively lower concentrations of urea. Drift correction standards in positions 19 and 20,29 and 30 . Quality control samples in 18 and 28. Results for analyses (concentrations in $\mathrm{mg} / 100 \mathrm{ml}$ ) are set out below.

$\begin{array}{lrrrrrrrrrr}\text { Peak number } & 11 & 12 & 13 & 14 & 15 & 16 & 17 & 18 & 19 & 20 \\ \text { Chart record result } & 201 & 206 & 57 & 52 & 208 & 46 & 42 & 53 & 99 & 100 \\ \text { Computer's result } & 201 & 207 & 55 & 51 & 210 & \text { Error } & 41 & 52 & - & - \\ \text { Peak number } & 21 & 22 & 23 & 24 & 25 & 26 & 27 & 28 & 29 & 30 \\ \text { Chart record result } & 211 & - & 36 & 204 & - & 25 & 211 & 59 & 100 & 100 \\ \text { Computer's result } & 215 & \text { Error } & 34 & 204 & \text { Error } & 24 & 210 & 56 & - & -\end{array}$

with alanine aminotransferase; monitoring of this channel on line still gives rise to occasional difficulties. Up to 10 analytical channels have been monitored simultaneously, signals being transmitted to the data-acquisition unit through the four analyser consoles (for instance, console 1: sodium potassium, chloride, bicarbonate, and urea; console 2: total protein and albumin; console 3 : calcium and phosphate; console 4: cholesterol), to test the multiplexing capability of the system. The efficiency of the computer in recognizing faults in the operation of AutoAnalyzers and the chemical acceptability of computer-calculated results have also been investigated.

ANALYSIS OF SPECIMENS: FAULT RECOGNITION Fault recognition programs relating to the acquisition of data on line from AutoAnalyzers have been assessed by testing their ability to reject faulty peaks, deliberately introduced (eg, Fig. 5); to reject unacceptable calibration curves; to detect faulty calibration curves which can nevertheless be used if the operator instructs the computer appropriately (eg, Fig. 4); and to detect unacceptable degrees of instrumental drift.

When a peak is rejected as faulty by the computer, it may fail to meet more than one of the specified criteria (Fig. 2 and Table V) but only one error message appears on the on-line Teletype. For instance, a peak affected by carryover from the previous sample (Fig. 6) could be rejected on the basis of insufficient rising readings (error 38), or the peak may appear early (error 35 ), or no peak may appear within the time window due to excessive carryover and a 'peak late' message may be printed out (error 36). This has prevented a detailed individual analysis of each fault recognition program, and the assessments have been restricted to determining the efficiency with which faults have been detected, without specifying in detail the nature of the fault on each occasion. In general, these programs have worked efficiently, and faults have been detected much more rapidly than by the human operator.

Occasionally the computer has failed to reject peaks that appear unduly sharp on the chart record, the urual causes for these sharp peaks being specimens insufficient for satisfactory analysis, or a temporary block on the sample line. It may be possible to reject these faulty peaks by narrowing the time window within which peaks can be accepted; Table V shows that the time windows have been set wide, so as to allow for considerable variation in the arrival of the top of a peak. An alternative method might be to include in each peak recognition program a specification for the number of readings required within, for instance, $\pm 3 \%$ of the peak reading, instead of basing peak recognition and 
TABLE VI

RECOGNITION OF INSUFFICIENT SPECIMENS

\begin{tabular}{|c|c|c|c|c|c|c|c|c|c|c|c|}
\hline \multirow[t]{2}{*}{ Sample } & \multirow{2}{*}{$\begin{array}{l}\text { Aspiration } \\
\text { Time } \\
\text { (seconds) }\end{array}$} & \multicolumn{2}{|c|}{ Urea $(\mathrm{mg} / 100 \mathrm{ml})$} & \multicolumn{2}{|c|}{ Sodium (m-equiv/l) } & \multicolumn{2}{|c|}{ Potassium (m-equiv|l) } & \multicolumn{2}{|c|}{ Chloride (m-equiv/l) } & \multicolumn{2}{|c|}{ Bicarbonate (m-equiv/l) } \\
\hline & & $C^{1}$ & $T^{2}$ & $C$ & $T$ & $C$ & $T$ & $C$ & $T$ & $C$ & $T$ \\
\hline 11 & 20 & $\mathrm{E}^{3}$ & $R^{4}(85)$ & E & $R(115)$ & $\mathbf{E}$ & $R(4 \cdot 4)$ & E & $\mathbf{R}(70)$ & E & $R(15)$ \\
\hline 12 & 40 & 114 & 112 & 142 & 142 & $5 \cdot 4$ & 5.4 & 93 & 94 & 18 & 19 \\
\hline 13 & 25 & 93 & R (92) & $\mathrm{E}$ & $R(121)$ & E & $R(4 \cdot 6)$ & E & $\mathbf{R}(80)$ & $\mathbf{E}$ & R (17) \\
\hline 14 & 40 & 108 & 107 & 142 & 142 & 5.4 & 5.4 & 96 & 96 & 19 & 19 \\
\hline $15(\mathrm{QC})$ & 40 & 50 & 48 & 139 & 138 & $4 \cdot 6$ & $4 \cdot 6$ & 104 & 104 & 11 & 13 \\
\hline 16 & 30 & 100 & 100 & $\mathrm{E}$ & 127 & E & 4.8 & 87 & 89 & $\mathrm{E}$ & 17 \\
\hline 17 & 40 & 111 & 108 & 143 & 141 & 5.4 & $5 \cdot 3$ & 97 & 97 & 19 & 19 \\
\hline 18 & 35 & 103 & 102 & 136 & 135 & $5 \cdot 1$ & $R^{5}(5 \cdot 1)$ & 94 & 95 & 18 & 19 \\
\hline 19 (Drift) & 40 & - & 98 & - & 139 & - & 3.9 & - & 102 & - & 20 \\
\hline 20 (Drift) & 40 & - & 100 & - & 140 & - & $4 \cdot 0$ & - & 104 & - & 20 \\
\hline 21 & 20 & $\mathbf{E}$ & $R(81)$ & $\mathrm{E}$ & R (110) & E & $R(4 \cdot 3)$ & E & $R(71)$ & E & R (15) \\
\hline 22 & 40 & 109 & 107 & 142 & 142 & $5 \cdot 5$ & 5.4 & 95 & 95 & 19 & 19 \\
\hline 23 & 25 & 92 & R (91) & E & $R(120)$ & $\mathbf{E}$ & $R(4 \cdot 6)$ & $E$ & R (79) & $\mathrm{E}$ & R (17) \\
\hline 24 & 40 & 110 & 108 & 143 & 143 & 5.4 & 5.5 & 95 & 96 & 18 & 19 \\
\hline 25 & 30 & 102 & 102 & 126 & 129 & E & $\mathbf{R}^{5}(5.0)$ & 87 & 89 & 17 & 18 \\
\hline 26 & 40 & 112 & 111 & 143 & 143 & $5 \cdot 5$ & $5 \cdot 5$ & 98 & 98 & 19 & 19 \\
\hline 27 & 35 & 113 & 113 & 138 & 138 & $5 \cdot 3$ & $R^{5}(5 \cdot 3)$ & 98 & 98 & 18 & 19 \\
\hline $28(\mathrm{QC})$ & 40 & 52 & 52 & 138 & 139 & $4 \cdot 6$ & $4 \cdot 7$ & 103 & 103 & 11 & 13 \\
\hline 29 (Drift) & 40 & - & 100 & - & 139 & - & $3 \cdot 8$ & - & 104 & - & 20 \\
\hline 30 (Drift) & 40 & - & 100 & - & 140 & - & 4.0 & - & 104 & - & 20 \\
\hline
\end{tabular}

Concentrations for the rejected peaks calculated by a technician are shown in brackets. Except where noted (drift and QC $=$ quality control) all samples were from the same pool of plasma. Rate of analysis is 60/hour; normally sample: wash ratio, 2 : 1

${ }^{1} \mathrm{C}=$ Computer

${ }^{2} \mathbf{T}=$ Technician

${ }^{3} \mathrm{E}=$ error message

${ }^{\mathbf{4}} \mathbf{R}=$ peak rejected by technician

${ }^{5}$ Rejected by technician because of irregularity on top of peaks

acceptance mainly on the minimum numbers of rising and falling readings and on an acceptable arrival time. These shortcomings of the present program should not be overstressed, however, as Fig. 7 shows the chart record for the urea channel in an experiment where some of the specimens being analysed for their content of urea, sodium, potassium chloride, and bicarbonate had their sampling time deliberately shortened, and Table VI compares the ability of the computer and of a technician who

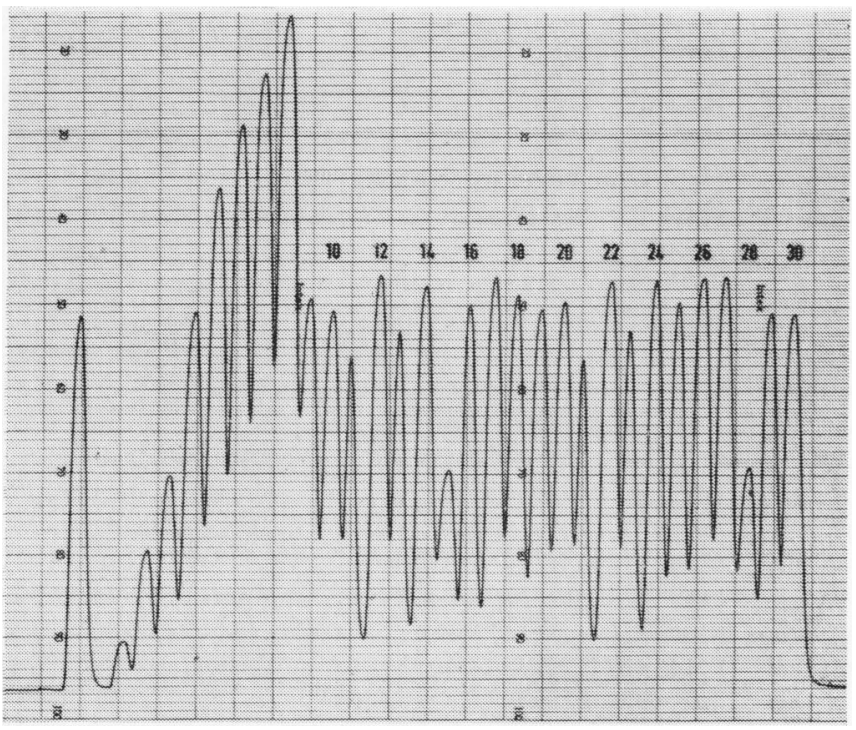

FIG. 7. Recognition of samples that are insufficient for proper analysis. Urea analyses (60/hr; sample: wash ratio, 2:1). Specimens in some positions have been analysed for periods shorter than 40 seconds. Comparisons between concentrations calculated by computer and by a technician unaware of which peaks were faulty are given in Table VI. 


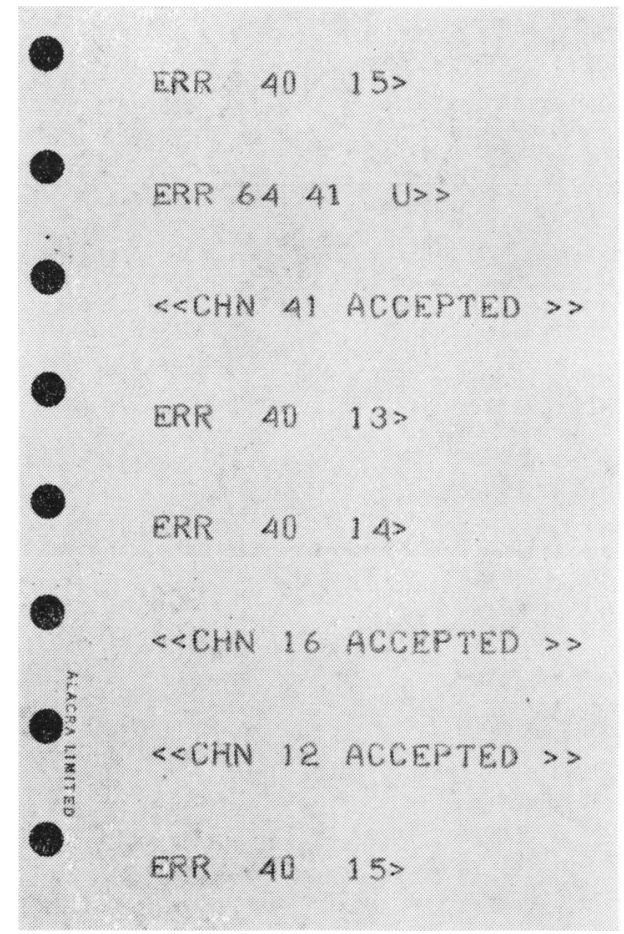

FIG. 8. Messages appearing on the Teletype in an experiment where the computer was on line to channels 12 (urea), 16 (bicarbonate), and 41 (cholesterol); channels 13, 14 , and 15 were not in operation, but the computer was programmed to receive signals from these channels. The error messages represent long waits for the arrival of peaks (error 40), each followed by a channel identification number. Error 64 reported a fault on the calibration curve for which the operator typed in a 'use' instruction, and the computer immediately printed out a message to say that channel 41 was accepted. Channels 12 and 16 had their calibration curves accepted without difficulty.

works in another laboratory to detect unsatisfactory peaks; the computer has been no less successful than the technician, but the computer would not tire over the examination of peaks by rigid criteria in a longer run.

Examples of calibration curve acceptance messages and error messages appearing on the on-line Teletype are given in Figure 8. When faults occur, in addition to an error message appearing on the on-line Teletype, a red light glows on the analyser console on the laboratory bench, and another on the front panel of the data-acquisition unit. These lights stay on for one minute, unless another fault appears in relation to the succeeding peak. For some faults no action is required by the operator. However, if the error message requires a decision but no instruction is given, the message is typed out again five minutes later and again after 10 and finally after 11 minutes if still no instruction has been typed in; thereafter, if no action is taken, the computer stops monitoring the channel. Examples of faults where the error messages demand an answer include faults detected on the calibration curves and on the drift correction standards. Some of the faults on calibration curves cannot be overcome by an instruction from the operator, and the relevant analytical channel must be closed down or restarted; both the close-down and restart routines have been tested and can be carried out satisfactorily. The computer also automatically ceases to monitor a channel if four faulty peaks occur in succession.

ANALYSIS OF SPECIMENS: CHEMICAL ACCEPTABILITY Assessment of acceptibility on analytical grounds has included paired comparisons between the results of analyses of patients' specimens and quality control samples, the analyses being carried out first with AutoAnalyzers operating under routine laboratory conditions and then repeated on a second AutoAnalyzer system where the signals from the photocells were being monitored by the computer. For these paired analyses, agreement (Table VII) between the two sets of analytical runs has been at least as good as for between-batch comparisons on the routine analytical methods.

The results calculated and printed out from the computer have also been compared with the results obtained by the standard methods of processing data from AutoAnalyzers, involving the reading off of peaks from the chart records and calculation of concentrations for specimens; in this set of comparisons, both groups of results derived from the same analytical run. The importance of this latter set of comparisons lies in the fact that the chart records will provide the back-up system when the laboratory is using the computer routinely, since the chart records allow these processes of calculation and reporting to be performed, if necessary, independently of the computer itself. Closer agreement has been obtained in this set of analytical comparisons (Table VIII), which are not subject to between-batch errors, but the computer has been very much quicker at applying the appropriate drift corrections and punching out the results of each batch of analyses for printing up the results on the off-line Teletype (Fig. 5) than the technicians responsible for reading and processing the data from the chart records.

ANALYSIS OF SPECIMENS: OUTPUT OF RESULTS The output of calculated results at first appeared on the keyboard of the on-line Teletype, but latterly the amount of information from the computer appearing 
TABLE VII

PAIRED COMPARISONS OF ANALYTICAL PERFORMANCE ${ }^{1}$

Analysis

Method $^{2} \quad$ Number of Paired

Observations ( $n$ )

$\sqrt{\frac{\text { Standard Deviation }}{n}}$

Range of Concentrations over which Paired Comparisons Made

Plasma or Serum

Urea

Sodium

Potassium

Chloride

Bicarbonate

Alkaline phosphatase

Bilirubin

Alanine aminotransferase

Calcium

Phosphate

Total protein

Total protein blank

Albumin

Creatinine

Cholesterol

Uric acid

Iron

Iron-binding capacity

Urine

Creatinine

Phosphate
A
N21B II
N21B II
N21B II

N8B

B

N12

N44

C

D

N14B 124

N14B $\quad 71$

E

N11B

N24a

F 111

G $\quad 107$

$3.31 \mathrm{mg} / 100 \mathrm{ml}$

$1.38 \mathrm{~m}$-equiv/l

$0 \cdot 15$ m-equiv/l

$2 \cdot 20$ m-equiv/l

2.78 m-equiv/1

0.28 King-Armstrong units $/ 100 \mathrm{ml}$

$0.07 \mathrm{mg} / 100 \mathrm{ml}$

No results

$0.18 \mathrm{mg} / 100 \mathrm{ml}$

$0.25 \mathrm{mg} / 100 \mathrm{ml}$

$0.11 \mathrm{~g} / 100 \mathrm{ml}$

$0.03 \mathrm{~g} / 100 \mathrm{ml}$

$0.10 \mathrm{~g} / 100 \mathrm{ml}$

$0.16 \mathrm{mg} / 100 \mathrm{ml}$

$6.6 \mathrm{mg} / 100 \mathrm{ml}$

$0.38 \mathrm{mg} / 100 \mathrm{ml}$

$6.2 \mu \mathrm{g} / 100 \mathrm{ml}$

$14.4 \mu \mathrm{g} / 100 \mathrm{ml}$

$1.9 \mathrm{mg} / 100 \mathrm{ml}$

$1.8 \mathrm{mg} / 100 \mathrm{ml}$
10-300

114-156

$2 \cdot 4-7 \cdot 7$

84-115

10-36

$5-30$

$0 \cdot 2-8 \cdot 0$

$8 \cdot 0-12 \cdot 0$

$1 \cdot 9-11 \cdot 4$

$1 \cdot 8-9 \cdot 3$

$0 \cdot 1-1 \cdot 1$

$1 \cdot 3-5 \cdot 2$

$0 \cdot 5-9 \cdot 4$

119-365

2.6-13.9

$22-455$

$165-645$

29-198

3-59

'Standard deviations between pairs of analyses performed on specimens obtained from patients. Analyses were first carried out by the department's routine methods, in response to requests received by the laboratory. Analyses were repeated the next day, using AutoAnalyzers on line to the Elliott 903 computer and the computer-calculated results were compared with the previous day's results. The overnight delay before repetition of analyses partly accounts for the discrepancies between pairs of bicarbonate analyses.

${ }^{2}$ Where the method used does not differ from the Technicon N-method description, the code number is given in full. References for the others as follows:-

A Marsh, W. H., Fingerhut, B., and Miller, H. (1965). Clin. Chem., 11, 624-627.

B Sterling, R. E., Wilcox, A. A., Ware, A. G., and Umehara, M. K. (1964). Ibid., 10, 1112-1116.

C Gitelman, H. J. (1967). Analyt. Biochem., 18, 521-531.

D Young, D. S. (1966). J. clin. Path., 19, 397-399.

E Northam, B. E., and Widdowson, G. M. (1967). Ass. clin. Biochem., Tech. Bull. No. 11.

F Crowley, L. V. (1964). Clin. Chem., 10, 838-844.

G Young, D. S., and Hicks, J. M. (1965). J. clin. Path., 18, 98-102.

TABLE VIII

EXAMPLES OF PAIRED COMPARISONS OF METHODS OF CALCULATING RESULTS ${ }^{1}$

\begin{tabular}{|c|c|c|c|}
\hline Analyses & $\begin{array}{l}\text { Number of Paired } \\
\text { Observations }(n)\end{array}$ & $\begin{array}{l}\text { Standard Deviation } \\
\sqrt{\frac{\left(\Sigma \text { difference }^{2}\right)}{n}}\end{array}$ & $\begin{array}{l}\text { Range of Concentrations } \\
\text { over which Paired } \\
\text { Comparisons Made }\end{array}$ \\
\hline $\begin{array}{l}\text { Urea } \\
\text { Sodium } \\
\text { Potassium } \\
\text { Chloride } \\
\text { Bicarbonate } \\
\text { Creatinine } \\
\text { Calcium } \\
\text { Phosphate } \\
\text { Iron }\end{array}$ & $\begin{array}{r}584 \\
600 \\
589 \\
298 \\
572 \\
55 \\
167 \\
87 \\
40\end{array}$ & $\begin{array}{l}2.26 \mathrm{mg} / 100 \mathrm{ml} \\
0.66 \mathrm{~m} \text {-equiv/l } \\
0.05 \mathrm{~m} \text {-equiv } / \mathrm{l} \\
0.74 \mathrm{~m} \text {-equiv } / 1 \\
0.53 \mathrm{~m} \text {-equiv } / 1 \\
0.06 \mathrm{mg} / 100 \mathrm{ml} \\
0.16 \mathrm{mg} / 100 \mathrm{ml} \\
0.11 \mathrm{mg} / 100 \mathrm{ml} \\
2.03 \mu \mathrm{g} / 100 \mathrm{ml}\end{array}$ & $\begin{array}{c}10-300 \mathrm{mg} / 100 \mathrm{ml} \\
114-156 \mathrm{~m} \text {-equiv/1 } \\
2 \cdot 4-7 \cdot 7 \mathrm{~m} \text {-equiv } / 1 \\
84-115 \mathrm{~m} \text {-equiv/l } \\
10-36 \mathrm{~m} \text {-equiv/1 } \\
0 \cdot 5-8 \cdot 6 \mathrm{mg} / 100 \mathrm{ml} \\
3 \cdot 9-13 \cdot 3 \mathrm{mg} / 100 \mathrm{ml} \\
2 \cdot 1-10 \cdot 8 \mathrm{mg} / 100 \mathrm{ml} \\
51-312 \mu \mathrm{m} / 100 \mathrm{ml}\end{array}$ \\
\hline
\end{tabular}

'Standard deviations between paired calculations of results for single analyses when the Elliott analyser console was being used to transmit signals to the Elliott 903 computer. The comparisons are between (1) results calculated from the chart records by standard methods of calculation, and (2) results printed out after the computer had performed its calculations. The close agreement shows that the chart records can be used for back-up purposes. 


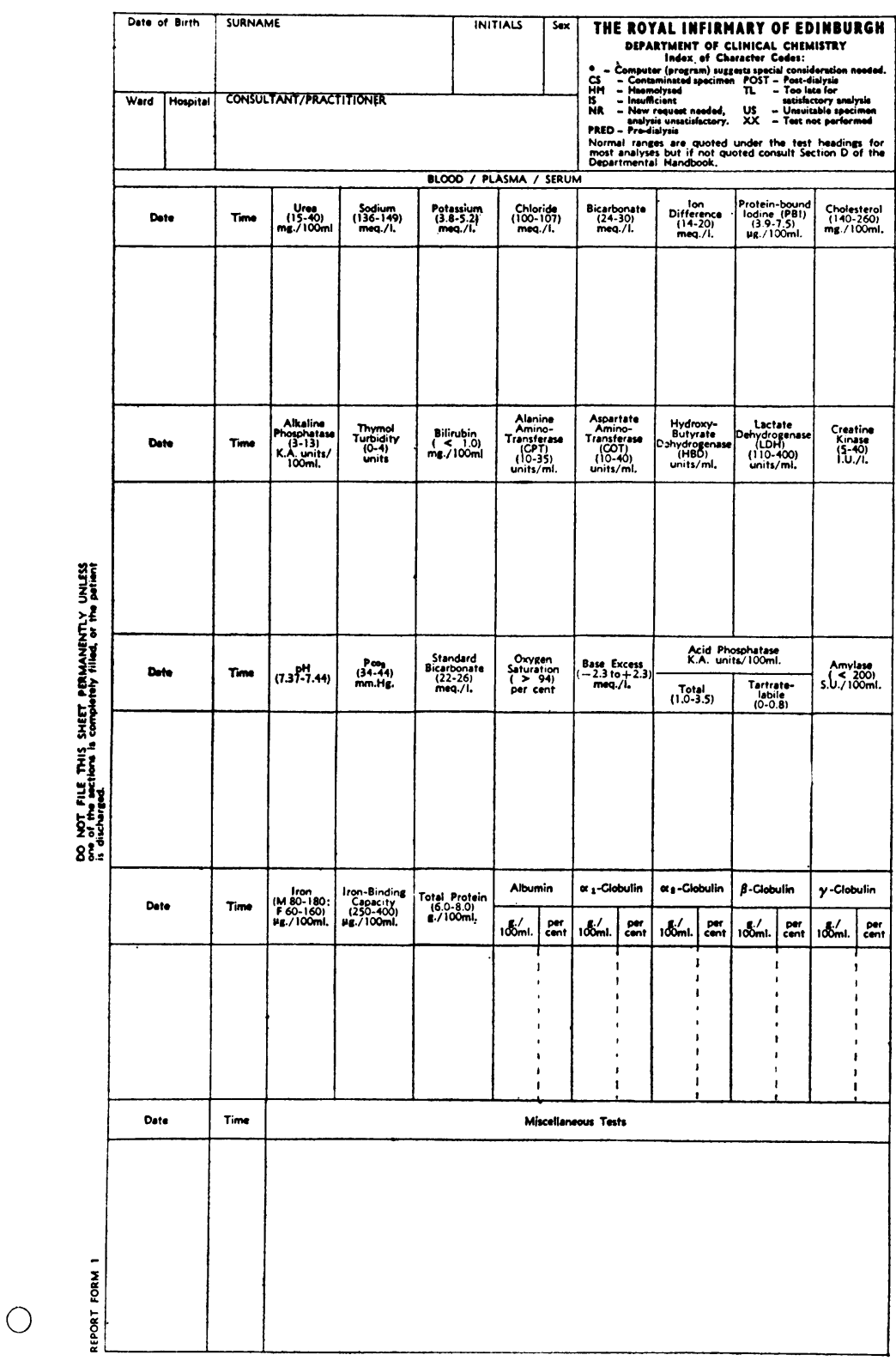

FIG. 9. Preprinted continuous stationery showing layout adopted for cumulative reports. Output programs for these reports have not yet been tested. This format is for analyses on blood. on this keyboard has been greatly reduced following the writing of the on-line monitoring and calculation programs on to magnetic tape; output of computed data at present occurs via the paper-tape punch (Fig. 5). These results are printed up to more decimal places than will appear on the final reports, and individual sets of results have still to be identified by their positions on the AutoAnalyzer sampler turntables. At a later stage, the output of results is planned to appear as cumulative records on preprinted stationery (Figs 9 and 10), printed up either on line (IBM output writer) or off line after initial output on paper tape; investigation of this aspect of the overall programme of work has to wait until after the programs for laboratory accession procedures and the organization of records on file have been evaluated fully.

Results for analyses of serum total protein and 


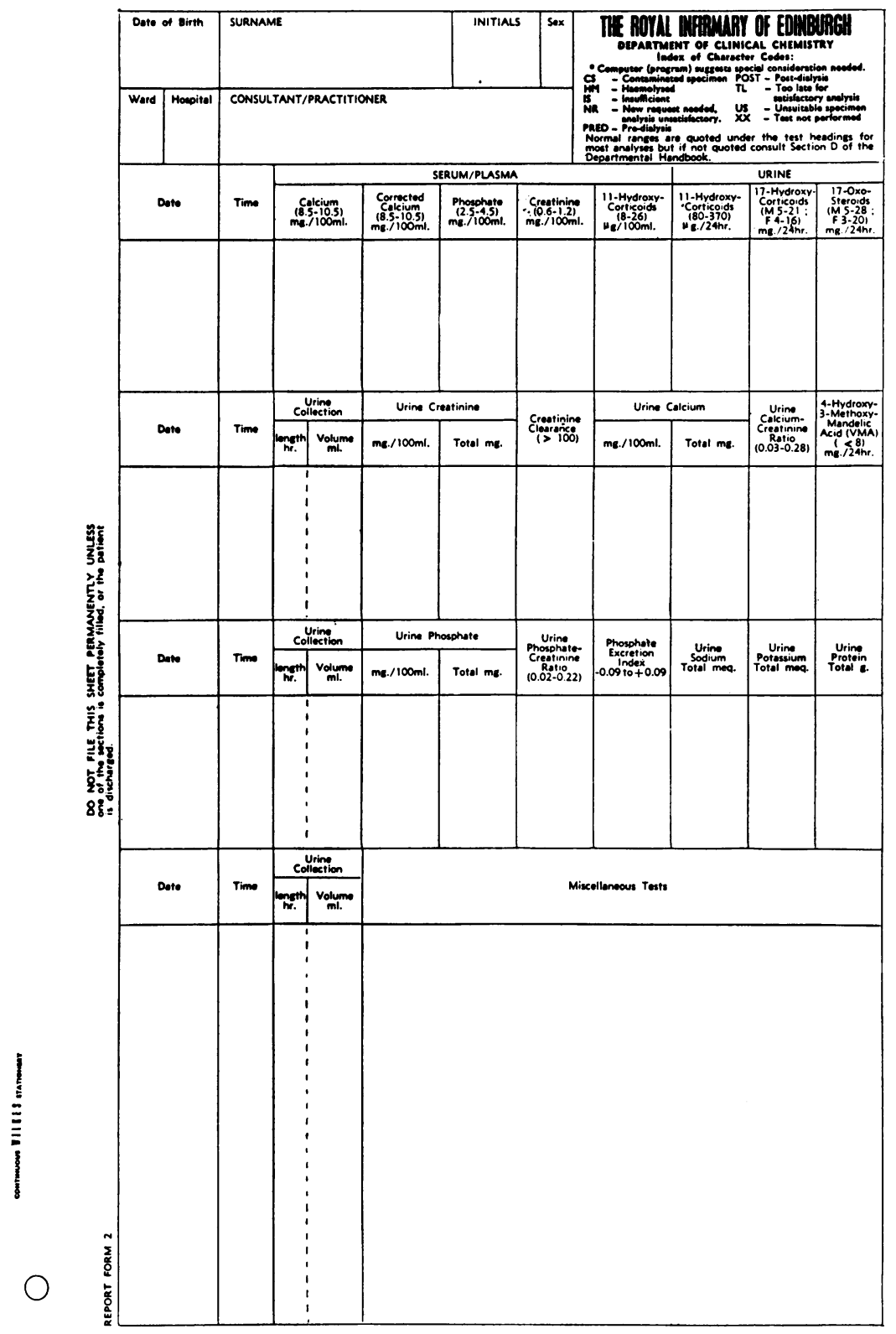

FIG. 10. Preprinted continuous stationery showing layout adopted for cumulative reports. This format is mainly for analyses on urine. their corresponding blank determinations are at present calculated separately and printed up separately; the program which allows for the automatic subtraction of blanks by interrelating the results of these two separate analytical runs has not yet been tested.

\section{LABORATORY ACCESSION PROCEDURES}

INPUT OF DATA TO THE COMPUTER FROM REQUEST FORMS Information carried on request forms is at present entered via the keyboard of the on-line Teletype, and the computer applies several checks to the accuracy of these operations. Thereafter, when instructed to do so, the computer sorts this information into work sheets and issues these via the tape punch for printing up off line. Figures 11 and 12 show the pattern of keyboard entries and the appearance of a computer-prepared work sheet. Steps in the present program for preparing work sheets are summarized in the succeeding paragraphs.

Date of birth registration numbers (six figures and first letter of surname) for up to 24 patients are entered; 
$I N N>>$

START INPUT

$191015 R \quad 2409020$ 291002K 000000B $320605 F \quad 000000 S$ 031512R 110612P

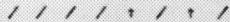

$230605 \mathrm{~F} \quad 030512 \mathrm{~K} \quad 1602238000000 \mathrm{~K}$ 2506115 080600T $210410 \mathrm{H}$ 09044R

$1,11,1$,

$090404 R \quad 1704136 \quad 200113 \mathrm{M} 2003090180201 \mathrm{M} 2505095 \quad 141003 \mathrm{~W} 210635 \mathrm{~B}$

$1,1,1,1$

$+$

$191015 \mathrm{R}$ RUSSELL. I $M$ SCD * - >

$280169 \times 112$ - ELU,AP T090013>

$2409020 / 1$ DOTLE A M 16 - . Y Y

$-X 113-a$ U. AP T0900>>

$291002 K / 1 \mathrm{KING} S F 14 \mathrm{~A} \mathrm{CIT} \mathrm{JMM} \quad Y>>$

- X134- ELU, $\mathrm{C}$ T0900 S>>

$-\times 135-C C V 1400 \quad S>>$

$-\times 136-F E, I B C>>$

$000000 B / 1$ BROWNLIE A M SCD - N N

$0000008 / 2$ BUCHANAN $R$ M 4 CHA - N>>

$000000 \mathrm{~B}$ BROWN $3 \mathrm{M}--\mathrm{GP}>>$

$-X 146-$ DL U, AP T1500>>

$000000 S / 1$ SCOTLAND J M BA GIT JWC N>>

000000S STEWART A M $6-\infty>$

$-\times 185-$ ELU TO900 $>>$

$110612 \%$ PAL.MER $R M 26-$ WWD $>$

$-\mathrm{X} 177-\mathrm{C}-\mathrm{S}>>$

$-\mathrm{X} 178-\mathrm{CC} V 1400>>$

FIG. 11. Entry of information from request forms. A series of registration numbers consisting of the date of birth and first letter of surname (the Royal Infirmary uses the date of birth for identification purposes; it does not issue a unique identifying number for each patient). These numbers are examined a line at a time (eight numbers each) and acceptable numbers are indicated by a / mark; rejected numbers (two examples in first line) are entered again at the start of the second line. At the end of the entry (24 numbers maximum), the computer prints these numbers back one at a time together with full identification of any patient on file who has the number under consideration. If the identifying data match up, the operator types in $Y$ followed by the information relating to the specimen (second and third patients in this list). If the patient is not on file (fourth patient), the operator types in $N$ and the number is printed back again. For patients new to the computer's records, full identification data and test request information are key punched. The computer also applies checks to test request codes (Table IX) and queries any unacceptable codings. $S$ indicates a further specimen for the same patient.

each line on the Teletype carriage accommodates eight of these numbers. On completion of a line of input, the computer rapidly checks the acceptability of these numbers, as dates of birth, before the typist proceeds to enter the next line, acceptance of a number being indicated by a slash mark (Fig. 11). If the date of birth is not known, a series of six zeros and the initial of the surname is entered as the 'registration number'.

When up to 24 registration numbers have been entered, the computer searches its records and prints these numbers back one at a time on the keyboard of the online Teletype. If there is already a patient on file corresponding to a particular registration number, the complete identification of that patient is printed back and the keyboard operator signifies whether the patient's data entered on the request form correspond with the information retrieved from the magnetic tape file; an opportunity exists at this stage for modifying individual items, eg, change of ward. Since the registration number is not unique, if the details for the patient retrieved by the 
TABLE IX

EXAMPLES OF TEST REQUEST CODES

\begin{tabular}{|c|c|c|c|}
\hline Analysis on Plasma or Serum & Code & Analysis on Urine & Code \\
\hline $\begin{array}{l}\text { Acid phosphatase (total and tartrate-labile) } \\
\text { Creatinine } \\
\text { Cholesterol } \\
\text { Electrolytes }{ }^{1} \text { and urea } \\
\text { Iron } \\
\text { Iron-binding capacity } \\
\text { Potassium } \\
\text { Liver function tests }{ }^{2} \\
\text { Urea } \\
\text { Uric acid }\end{array}$ & $\begin{array}{l}\text { AP } \\
\text { C } \\
\text { COL } \\
\text { ELU } \\
\text { FE } \\
\text { IBC } \\
\text { K } \\
\text { LFT } \\
\text { U } \\
\text { UA }\end{array}$ & $\begin{array}{l}\text { 5-hydroxy-indole acetic acid } \\
\text { Creatinine concentration } \\
\text { Calcium concentration } \\
\text { 11-hydroxycorticosteroids } \\
\text { 17-hydroxycorticosteroids } \\
\text { Uric acid } \\
\text { Analysis on faeces } \\
\text { Calcium } \\
\text { Fat } \\
\text { Potassium }\end{array}$ & $\begin{array}{l}\text { HAA } \\
\text { CC } \\
\text { CAC } \\
\text { OHS } \\
\text { HYD } \\
\text { UUA } \\
\text { SCA } \\
\text { FAT } \\
\text { SK }\end{array}$ \\
\hline
\end{tabular}

computer do not match with the information on the request form, the operator instructs the computer accordingly and the computer then prints out the registration number again on a new line. If there are already two or more patients on file with this registration number, their full identifying data are printed out one set at a time for comparison with the request form. If the patient is a new patient, after the computer has completed its search of past records for that particular registration number, the operator keys in the full identifying data following the printing back by the computer solely of the registration number.

After the patient has been identified as one previously on file, or the full identifying data have been entered, the date of the request and the details relating to the specimen (laboratory identification number followed by the investigations that have been requested) are entered, using codes for the tests (examples shown in Table IX); other relevant details, such as the length of collection of a sample of urine or an indication that the request is urgent, complete the entry. The computer then checks the entry for acceptability, and prints back queries in respect of illegal or incomplete entries; mispunchings of test codings, for instance, can be corrected.

These steps finish the entry of data for one request form, and the computer signifies that it has accepted each complete entry by automatically printing back the next registration number in the batch currently being processed. In this way, the data on a batch of request forms are progressively entered, it being important to keep the request forms in their correct order so as to expedite the process. It is essential to work systematically as otherwise test codes for one patient may be entered in relation to identifying data corresponding to another.

OUTPUT OF WORK SHEETS When data for one batch consisting of up to 24 request forms have been entered, further batches can be entered or the computer can be instructed, on completion of a batch of entries, to sort the information on tests that have been requested and prepare specified work sheets; these are then punched out for printing up off line on the Teletype (Fig. 12). Each work sheet specifies the order of analysis for 20 specimens, the first work sheet listing the standards to be analysed before

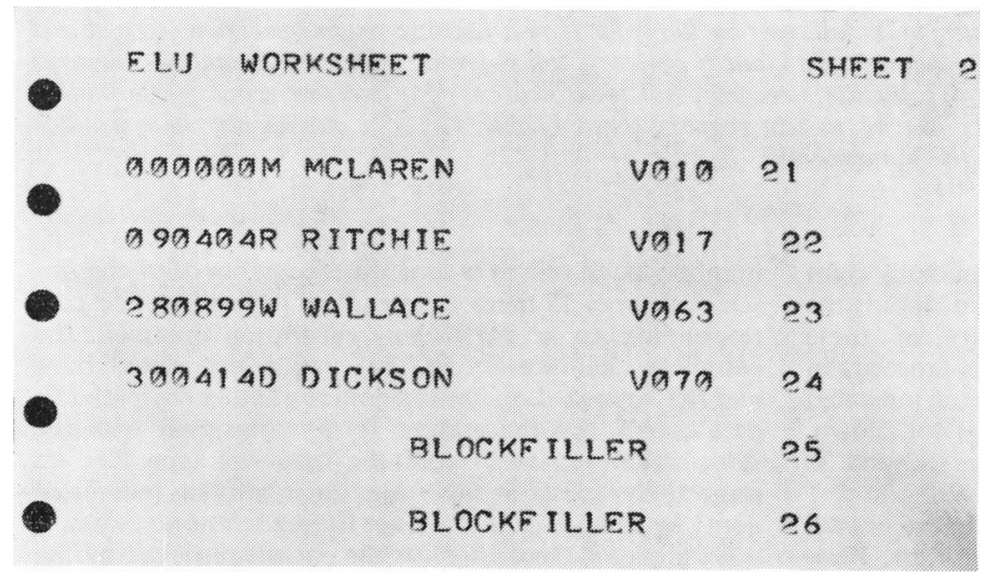

FIG. 12. Part of a computer-prepared work sheet for plasma electrolyte (sodium, potassium, chloride, and bicarbonate) and urea analyses. The work sheet is issued on punched tape and printed up on the off-line Teletype. 


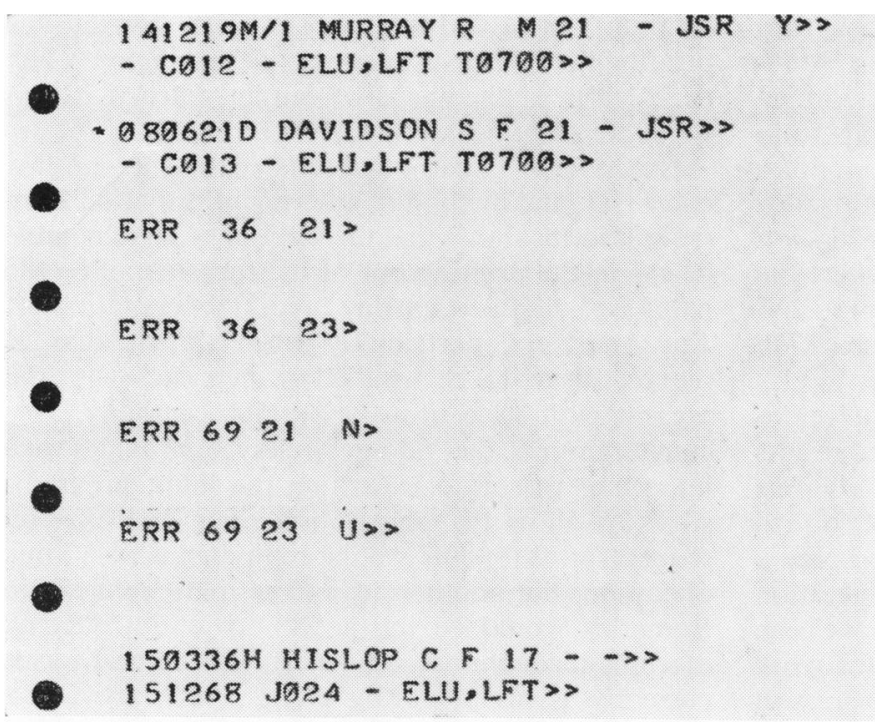

FIG. 13. Part of the printout appearing on the on-line Teletype when information was being entered from request forms at the same time as the computer was on line to protein (channel 21) and protein blank (channel 23) analyses. Immediately after a block of input (eight requests) had been completed a series of error messages appeared that had been held up by the input procedures. proceeding to print out the identifications for patients' specimens. If there are insufficient specimens to complete a work sheet, the computer has been instructed to designate the vacant spaces as 'blockfillers'.

EXPERIENCE WITH LABORATORY ACCESSION PROCEDURES The present system of entry of information from request forms suffers from the major drawback that no part of the data can be read into the computer until after a keypunching operation. This drawback, which is primarily a criticism of the request forms rather than of the method of entering information into the computer, will be considered in the discussion.

The entry of requests and the calling down of work sheets has been tested both with the computer performing no other functions, and with the computer simultaneously monitoring AutoAnalyzers, so as to simulate the conditions that obtain at the start of the day and later on. The ability to correct mispunchings, and the amendment of identifying information for patients already on file have also been tested.

The preparation of work sheets has not yet been fully evaluated as work has been temporarily held up by a fault that has been detected in the magnetic tape controller; this has been preventing the reading of the status of the controller during a back-space operation. It is, however, possible to comment on certain aspects relating to the input of data from request forms and the preparation of work sheets on the basis of experience gained so far.

The computer can successfully detect the entry of impossible dates of birth and of illegal test request codes, and the correction of these errors has been achieved satisfactorily. Some errors, eg, misspellings of names, entry of the wrong ward, or of a code corresponding to another test in place of the one requested, cannot be detected by the computer; if the operator sees these mistakes, the entry can be amended or else cancelled and re-entered. Obviously difficulties can arise if incorrect but computer-acceptable entries are made and the error is not detected until later; these errors can be made good, but the extent of the correction required will depend on whether or not work sheets have already been prepared that include the incorrectly entered request, and the various correction procedures have not all been tested yet.

The sorting of details from request forms and the preparation of work sheets has also begun to be evaluated, but the fault on the tape controller means that work sheets cannot be obtained when the on-line adapter on the data-acquisition unit is switched on, and even at other times the recall of work sheets has not been uniformly successful. The preliminary experiments have already shown, however, that unacceptable delays can occur in the output via the on-line Teletype of messages relating to the operation of AutoAnalyzers, when the entry of information from request forms is also taking place. Figure 13 shows that a series of error messages was held up until the entry of a block of information about requests had been completed, and these hold ups have resulted in the computer automatically ceasing to monitor some channels when it has failed to receive the necessary instruction relating to certain categories of error message sufficiently quickly. Similar delays in the output of error messages may be anticipated when the computer is organizing requests for the output of work sheets, but this possibility cannot be tested until the preparation of work sheets can take place at the same time as the monitoring of the AutoAnalyzers.

\section{DISCUSSION}

The computer system described in this paper has been used successfully for on-line acquisition of data from up to 10 channels of AutoAnalyzer equipment at one time. Programs for peak recognition, calibration curve validation, and drift correction have 
been evaluated, and the acceptability on analytical grounds of the computer-calculated results established for 19 different chemical analyses performed on AutoAnalyzers. Since acquisition of signals from AutoAnalyzers for transmission to the computer involves modification to the colorimeter settings for some of the analytical channels, the demonstration that these modifications did not adversely affect the reliability of the chemical analyses (Table VII), and that the chart records could still be used for back-up purposes (Table VIII) was important.

On those days when the programme of development work allows it, the computer-calculated results are now used for reporting purposes, but this involves transcription from the Teletype printout on to report forms, and the computer will not become a regular component of the laboratory's operation until the other aspects of the overall system have been fully evaluated, particularly the programs for work sheet preparation and for records storage with output of cumulative reports. The reliability of the AutoAnalyzer-monitoring part of the system has begun to be tested under daily working conditions, and a big advantage of on-line real-time acquisition of data from AutoAnalyzers has already been clearly demonstrated, namely, the rapid printout by the computer of fault-recognition messages. The checks on analytical performance are applied rapidly and systematically by the computer, and the weak link in the process-control loop is now clearly seen to be the AutoAnalyzer operator; the correction of instrumental malfunction by human intervention is very slow in comparison with the speed of fault recognition by the computer. Ideally, the loop will eventually be closed by servocontrol mechanisms operating appropriately in response to faultrecognition procedures carried out by the computer.

It would be premature to comment upon the reliability of different components of the computer system on the basis of experience gained so far. There has been a substantial amount of down time, particularly on the data-acquisition unit and the magnetic tape unit, but some down time has to be accepted with a system involving development. At a later stage, under routine working conditions, temporary faults can be anticipated and arrangements have been made to minimize the effects of some of these by the purchase of a spare Teletype, tape reader, and tape punch. Until the output programs have been tested, no decision has been taken about the purchase of additional output printing equipment; it is forecast, however, that the present equipment will prove insufficiently rapid for the task of preparing cumulative reports. Only experience will show whether a second IBM output writer (interfaced to the computer for on-line printing), or a battery of Teletypes (for off-line printing) or a line-printer can best overcome any deficiencies in the speed of output, particularly as encountered at peak periods of reporting.

Experience already gained with the on-line conversational method of entering information from request forms shows that there could be unacceptable delays in the printing out of messages detailing the nature of faults occurring with the operation of AutoAnalyzers, particularly when the number of request forms to be handled is increased from the present pilot scale up to about 500 each day. This congestion on the on-line Teletype provides one important reason for rewriting the input programs so as to allow the preparation of information on request forms for entry to the computer as an off-line operation, but another advantage that could derive from this would be the possibility of introducing machine-readable request forms. The request forms currently in use (Whitby et al, 1968) provide a simple back-up system for reporting purposes, but they have serious disadvantages as source documents for the computer as their use involves so much accurate transcription. It is, for instance, impossible for the computer to match up a new request with previous work done for the same patient if the date of birth is incorrectly entered on the form, or is omitted, or is key punched wrongly and the error not detected. Much of this repetitive key punching in the laboratory would be eliminated, and the problem of correct and consistent identification of patients greatly reduced, if the records department were to provide each case-record folder at the time of registration with a set of machine-readable laboratory request forms bearing full personal identification data. These forms could, for instance, be 80-column punched cards (Whitehead, 1965, 1968) or edge punched cards, which would be more appropriate for the Elliott 903 computer system; on receipt of such a request form with its specimen, the key punching in the laboratory would be restricted to entering the variable data detailing the nature of the request, and even this could be further reduced if suitable mark-sensing procedures could be introduced for doctors to detail at source the tests requested in a machine-readable way.

This report is necessarily incomplete because it describes the progress achieved so far in the introduction of a small computer into a large clinical chemistry laboratory. The programme of development work could stop now and the system be used for routine monitoring and calculation of results from several AutoAnalyzer channels; this would in itself achieve a major reduction in the repetitive chart-reading and calculation procedures carried out by technicians. However, to stop the programme 
of work at this stage would leave untouched the problem of matching up results with their report forms, and would mean the acceptance of transcription of results from the Teletype printout which deals with only one analytical channel at a time; the preparation of reports and records of laboratory work would remain largely a manual process. At present, therefore, many additional advantages that may be derived from this computer system still remain to be explored, such as the preparation of printed reports matching the analytical findings with the appropriate patient, and the preparation of cumulative summary reports for patients undergoing repeated investigation. Specifications have been drawn up so that the computer printout will automatically attach an asterisk to results that fall outside prescribed limits, or to draw attention to significant changes occurring in serially performed determinations. At a later stage, when the computer files hold sufficient data, detailed assessments of the different patterns of use made of the laboratory should be much more practicable than the present limited manually performed reviews.

\section{SUMMARY}

An Elliott 903 computer system has been used for six months for the on-line real time acquisition of data from AutoAnalyzers operating in parallel with the equipment used to perform the hospital's routine chemical investigations. Signals are led from the colorimeter or flame photometer to an analyser console, sited on the laboratory bench, and are here amplified for transmission to the data-acquisition unit for input to the computer. Programs for peak recognition, calibration curve validation, drift correction, and calculation routines have been tested for 19 chemical analyses. Fault recognition programs have also been investigated.

The results computed for analyses performed on specimens from patients showed close agreement with the corresponding results obtained from a second analytical run in which the specimens were analysed by AutoAnalyzers that were not on line to the computer, the chart records being processed by standard methods for the calculation of results.

With several methods, it is necessary to adjust the settings on the AutoAnalyzer colorimeter so that signals will fall within the range required for amplification and transmission to the computer. Part of the amplified signals are also attenuated for transmission to the AutoAnalyzer recorder amplifier, and it has been shown that the chart records can be used for back-up purposes.

The multiplexing capability of the data-acquisition unit has been tested. Ten AutoAnalyzer channels have been monitored simultaneously on line, the signals being transmitted to the data-acquisition unit from four analyser consoles, each of which has the capacity to accept signals from up to eight channels.

The output of calculated results from the computer is at present on punched paper tape for printing up off line. Results are identified by sample cup position, and are issued separately for each analytical channel. These computer-calculated results have begun to be used for reporting purposes, but at present require transcription on to standard laboratory report forms.

Information carried on request forms is entered via the on-line Teletype in a conversational mode. Evaluation of this process and of the programs for sorting this information into work sheets has begun, and experience so far indicates that the preparation of the input should be reprogrammed as an off-line operation, preferably combining this with the use of machine-readable request forms.

It is a pleasure to acknowledge the contribution of many members of the staff of Elliott Automation Ltd, and particularly the close involvement and interest of Mr G. E. Sims and Mr A. T. Gough. The project has been generously supported by a grant from the South-Eastern Regional Hospital Board, Scotland, and has been carried out under the auspices of the National Research Development Corporation. Many of the departmental staff have helped greatly with this work, and our thanks are due particularly to Dr D. W. Moss, Mr J. Proffitt, Miss A. Nicoll, and Mr R. S. McMaster.

\section{REFERENCES}

Blaivas, M. A. (1966). Application of a process control computer in the automated clinical chemistry laboratory. In Automation in Analytical Chemistry, edited by L. T. Skeggs, pp. 452-457. Mediad, New York.

-, and Mencz, A. H. (1967). Progress report on the use of a computer in the automated clinical chemistry laboratory. In Automation in Analytical Chemistry, Vol. I, pp. 368-372.

- - (1968). Improved standardization and peak analysis utilizing a process control computer with AutoAnalyzer systems. In Automation in Analytical Chemistry, Vol. 1, pp. 133136.

Flynn, F. V. (1965). Computer-assisted processing of biochemical test data. In Progress in Medical Computing, pp. 46-51. Elliott Medical Automation, London, 1965.

(1966). Use of a computer by a clinical chemistry service. Proc. roy. Soc. Med., 59, 779-782.

-, Piper, K. A., and Roberts, P. K. (1966). Equipment for linking the AutoAnalyzer to an off-line computer. J. clin. Path., 19, 633-639.

Gould, H. E. (1968). Computer automation in the clinical laboratory. In Automation in Analytical Chemistry, Vol. I, p. 141-146. Mediad, New York.

Gray, P., and Owen, J. A. (1969). Experience with on-line computer processing of data from an AutoAnalyzer complex. Clin. Chim. Acta, 24, 389-399.

Lathe, G. H., and Mitchell, F. L. (1966). Staffing of clinical biochemistry laboratories serving the National Health Service. Lancet, 1, 1413-1415.

Whitby, L. G., and Owen, J. A. (1965). Serial laboratory reports and records for chemical analyses. J. clin. Path., 18, 668-677.

- Proffitt, J., and McMaster, R. S. (1968). Experience with off-line 
processing by computer of chemical laboratory data. Scot. med. J., 13, 181-191.

Whitehead, T. P. (1965). Computer-assisted statistical uses of laboratory data. In Progress in Medical Computing, pp. 52-56.
Elliott Medical Automation, London, 1965.

(1968). The use of laboratory screening procedures in clinical biochemistry. Bio-med. Engng., 3, 467-472. 